NBER WORKING PAPER SERIES

THE PROMISE AND PROBLEMS OF PRICING CARBON:

THEORY AND EXPERIENCE

\author{
Joseph E. Aldy \\ Robert Stavins \\ Working Paper 17569 \\ http://www.nber.org/papers/w17569 \\ NATIONAL BUREAU OF ECONOMIC RESEARCH \\ 1050 Massachusetts Avenue \\ Cambridge, MA 02138 \\ November 2011
}

The views expressed herein are those of the authors and do not necessarily reflect the views of the National Bureau of Economic Research.

NBER working papers are circulated for discussion and comment purposes. They have not been peerreviewed or been subject to the review by the NBER Board of Directors that accompanies official NBER publications.

(C) 2011 by Joseph E. Aldy and Robert Stavins. All rights reserved. Short sections of text, not to exceed two paragraphs, may be quoted without explicit permission provided that full credit, including $\odot$ notice, is given to the source. 
The Promise and Problems of Pricing Carbon: Theory and Experience

Joseph E. Aldy and Robert Stavins

NBER Working Paper No. 17569

November 2011

JEL No. D02,F18,H23,K32,L38,Q28,Q48,Q5,Q54,Q58

\begin{abstract}
$\underline{\text { ABSTRACT }}$
Because of the global commons nature of climate change, international cooperation among nations will likely be necessary for meaningful action at the global level. At the same time, it will inevitably be up to the actions of sovereign nations to put in place policies that bring about meaningful reductions in the emissions of greenhouse gases. Due to the ubiquity and diversity of emissions of greenhouse gases in most economies, as well as the variation in abatement costs among individual sources, conventional environmental policy approaches, such as uniform technology and performance standards, are unlikely to be sufficient to the task. Therefore, attention has increasingly turned to market-based instruments in the form of carbon-pricing mechanisms. We examine the opportunities and challenges associated with the major options for carbon pricing: carbon taxes, cap-and-trade, emission reduction credits, clean energy standards, and fossil fuel subsidy reductions.
\end{abstract}

Joseph E. Aldy

Harvard Kennedy School

Belfer 409, Mailbox 58

79 JFK Street

Cambridge, MA 02138

and NBER

joseph_aldy@hks.harvard.edu

Robert Stavins

JFK School of Government

Harvard University

79 JFK Street

Cambridge, MA 02138

and NBER

robert_stavins@harvard.edu 


\title{
The Promise and Problems of Pricing Carbon: Theory and Experience
}

\author{
Joseph E. Aldy and Robert N. Stavins ${ }^{1}$
}

\author{
For a Special Issue of The Journal of Environment and Development \\ Edited by Thomas Sterner and Maria Damon
}

\section{Introduction}

In a modern economy, nearly all aspects of economic activity affect greenhouse gas - in particular, carbon dioxide $\left(\mathrm{CO}_{2}\right)$ - emissions, and hence the global climate. To be effective, climate change policy must affect decisions regarding these activities. This can be done in one of three ways: (1) mandate businesses and individuals to change their behavior regarding technology choice and emissions; (2) subsidize businesses and individuals to invest in and use lower-emitting goods and services; or (3) price the greenhouse gas externality, so that decisions take account of this external cost.

By internalizing the externalities associated with $\mathrm{CO}_{2}$ emissions, carbon pricing can promote cost-effective abatement, deliver powerful innovation incentives, and ameliorate rather than exacerbate government fiscal problems. By pricing $\mathrm{CO}_{2}$ emissions (or, equivalently, by pricing the carbon content of the three fossil fuels - coal, petroleum, and natural gas), governments defer to private firms and individuals to find and exploit the lowest cost ways to reduce emissions and invest in the development of new technologies, processes, and ideas that could further mitigate emissions. A range of policy instruments can facilitate carbon pricing, including carbon taxes, cap-and-trade, emission reduction credits, clean energy standards, and fossil fuel subsidy reduction.

Some of these instruments have been used with success in other environmental domains, as well as for pricing $\mathrm{CO}_{2}$ emissions. The U.S. sulfur dioxide $\left(\mathrm{SO}_{2}\right)$ cap-and-trade program cut U.S. power plant $\mathrm{SO}_{2}$ emissions more than 50 percent after 1990, and resulted in compliance costs one half of what they would have been under conventional regulatory mandates (Carlson, Burtaw, Cropper, and Palmer, 2000). The success of the $\mathrm{SO}_{2}$ allowance trading program motivated the design and implementation of the European Union's Emission Trading Scheme (EU ETS), the world's largest cap-and-trade program, focused on cutting $\mathrm{CO}_{2}$ emissions from power plants and large manufacturing facilities throughout Europe (Ellerman and Buchner, 2007). The U.S. lead phase-down of gasoline in the 1980s, by reducing the lead content per gallon of fuel, served as an early, effective example of a tradable performance standard (Stavins, 2003). These positive experiences provide motivation for considering market-based instruments as potential approaches to mitigating greenhouse gas emissions.

\section{Climate Change Policy Instruments for the Regional, National, or Sub-National Level}

We consider five generic policy instruments that could conceivably be employed by regional, national, or even sub-national governments for carbon pricing, including carbon taxes, cap-and-trade, emission reduction credits, clean energy standards, and fossil fuel subsidy reduction. First, however, we examine the possibility of relying on conventional environmental policy approaches, namely command-

\footnotetext{
1 Aldy is Assistant Professor of Public Policy, Harvard Kennedy School; Nonresident Fellow, Resources for the Future; and Faculty Research Fellow, National Bureau of Economic Research. Stavins is Albert Pratt Professor of Business and Government, Harvard Kennedy School; University Fellow, Resources for the Future; and Research Associate, National Bureau of Economic Research.
} 
and-control instruments, which have dominated environmental policy in virtually all countries over the past four decades.

\section{Command-and-Control Regulations}

Conventional approaches to environmental policy employ uniform standards to protect environmental quality. Such command-and-control regulatory standards are either technology-based or performance-based. Technology-based standards typically require the use of specified equipment, processes, or procedures. In the climate policy context, these could require firms to use particular types of energy-efficient motors, combustion processes, or landfill-gas collection technologies.

Performance-based standards are more flexible than technology-based standards, specifying allowable levels of pollutant emissions or allowable emission rates, but leaving the specific methods of achieving those levels up to regulated entities. Examples of uniform performance standards for greenhouse gas abatement would include maximum allowable levels of $\mathrm{CO}_{2}$ emissions from combustion (for example, the grams-of- $\mathrm{CO}_{2}$-per-mile requirement for cars and light-duty vehicles recently promulgated as part of U.S. tailpipe emission standards) and maximum levels of methane emissions from landfills.

Uniform technology and performance standards can - in principle - be effective in achieving some environmental purposes. But, given the ubiquitous nature of greenhouse gas emissions from diverse sources in an economy, it is unlikely that technology or ordinary performance standards could form the center-piece of a meaningful climate policy.

Furthermore, these command-and-control mechanisms lead to non-cost-effective outcomes in which some firms use unduly expensive means to control pollution. Since performance standards give firms some flexibility in how they comply, performance-based standards will generally be more cost effective than technology-based standards, but neither tends to achieve the cost-effective solution.

Beyond considerations of static cost-effectiveness, conventional standards would not provide dynamic incentives for the development, adoption and diffusion of environmentally and economically superior control technologies. Once a firm satisfies a performance standard, it has little incentive to develop or adopt cleaner technology. Regulated firms may fear that if they adopt a superior technology, the government may tighten the performance standard. Technology standards are worse than performance standards in inhibiting innovation since, by their very nature, they constrain the technological choices available.

The substantially higher cost of a standards-based policy may undermine support for such an approach, and securing political support may require a weakening of standards and hence lower environmental benefits. ${ }^{2}$

The key limitations of command-and-control regulations can be avoided through the use of market-based policy instruments. In the context of climate change, this essentially means carbon pricing.

\footnotetext{
${ }^{2}$ However, in special cases where emission monitoring and enforcement is particularly costly - such as for methane emissions in agriculture - a standards-based approach may be appropriate.
} 


\section{Carbon Taxes}

In principle, the simplest approach to carbon pricing would be through government imposition of a carbon tax (Metcalf, 2007). The government could set a tax in terms of dollars per ton of $\mathrm{CO}_{2}$ emissions (or $\mathrm{CO}_{2}$-equivalent on greenhouse gas emissions) by sources covered by the tax, or - more likely - a tax on the carbon content of the three fossil fuels (coal, petroleum, and natural gas) as they enter the economy. To be cost-effective, such a tax would cover all sources, and to be efficient, the carbon price would be set equal to the marginal benefits of emission reduction, represented by estimates of the social cost of carbon (Interagency Working Group on Social Cost of Carbon, 2010). Over time, an efficient carbon tax would increase to reflect the fact that as more greenhouse gas emissions accumulate in the atmosphere, the greater is the incremental damage from one more ton of $\mathrm{CO}_{2}$. Imposing a carbon tax would provide certainty about the marginal cost of compliance, which reduces uncertainty about returns to investment decisions, but would leave uncertain economy-wide emission levels (Weitzman, 1974).

The government could apply the carbon tax at a variety of points in the product cycle of fossil fuels, from fossil fuel suppliers based on the carbon content of fuel sales ("upstream" taxation/regulation) to final emitters at the point of energy generation ("downstream" taxation/regulation). Under an upstream approach, refineries and importers of petroleum products would pay a tax based on the carbon content of their gasoline, diesel fuel, or heating oil. Coal-mine operators would pay a tax reflecting the carbon content of the tons extracted at the mine mouth. Natural-gas companies would pay a tax reflecting the carbon content of the gas they bring to surface at the wellhead or import via pipelines or liquefied natural gas (LNG) terminals. Focusing on the carbon content of fuels would enable the policy to capture about $98 \%$ of U.S. $\mathrm{CO}_{2}$ emissions, for example, with a relatively small number of covered firms - on the order of a few thousand - as opposed to the hundreds of millions of smokestacks, tailpipes, etc. that emit $\mathrm{CO}_{2}$ after fossil fuel combustion.

A carbon tax would be administratively simple and straightforward to implement in most industrialized countries, since the tax could incorporate existing methods for fuel-supply monitoring and reporting to the regulatory authority. Given the molecular properties of fossil fuels, monitoring the physical quantities of these fuels yields a precise estimate of the emissions that would occur during their combustion.

A crediting system for downstream sequestration could complement the emission tax system. A firm that captures and stores $\mathrm{CO}_{2}$ through geological sequestration, thereby preventing the gas from entering the atmosphere, could generate tradable $\mathrm{CO}_{2}$ tax credits, and sell these to firms that would otherwise have to pay the emission tax. ${ }^{3}$

As fuel suppliers face the emission tax, they will increase the cost of the fuels they sell. This will effectively pass the tax down through the energy system, creating incentives for fuel-switching and investments in more energy-efficient technologies that reduce $\mathrm{CO}_{2}$ emissions.

The effects of a carbon tax on emission mitigation and the economy will depend in part on the amount and use of the tax revenue. For example, an economy-wide U.S. carbon tax of $\$ 20$ per ton of $\mathrm{CO}_{2}$ would likely raise more than $\$ 100$ billion per year. The carbon tax revenue could be put toward a variety of uses. It could allow for reductions in existing distortionary taxes on labor and capital, thereby

\footnotetext{
${ }^{3}$ Similar approaches could be undertaken to promote biological sequestration in forestry and agriculture and potentially emission-reduction projects ("offsets") in other countries. See discussion of Emission Reduction Credit programs below.
} 
stimulating economic activity and offsetting some of a policy's social costs (Goulder, 1995; Goulder and Parry, 2008). Other socially valuable uses of revenue include reduction of debt, and funding desirable public programs, such as research and development of climate-friendly technology. The tax receipts could also be used to compensate low-income households for the burden of higher energy prices, as well as compensating others bearing a disproportionate cost of the policy.

The implementation of a carbon tax (or any other meaningful climate policy instrument) will increase the cost of consuming energy and could adversely affect the competitiveness of energyintensive industries. This competitiveness effect can result in negative economic and environmental outcomes: firms may relocate facilities to countries without meaningful climate change policies, thereby increasing emissions in these new locations and offsetting some of the environmental benefits of the policy. Such "emission leakage" may actually be relatively modest, because a majority of the emissions in developed countries occur in non-traded sectors, such as electricity, transportation, and residential buildings. However, energy-intensive manufacturing industries that produce goods competing in international markets may face incentives to relocate and advocate for a variety of policies to mitigate these impacts (Aldy and Pizer, 2009).

Additional emission leakage may occur through international energy markets - as countries with climate policies reduce their consumption of fossil fuels and drive down fuel prices, those countries without emission mitigation policies increase their fuel consumption in response to the lower prices. Since leakage undermines the environmental effectiveness of any unilateral effort to mitigate emissions, international cooperation and coordination becomes all the more important. These competitiveness impacts on energy-intensive manufacturing could be mitigated through policy designs we discuss below. Also, it is important to keep in mind that these emission leakage effects exist with any meaningful climate policy, whether carbon pricing or command-and-control.

Real-world experience with energy pricing demonstrates the power of markets to drive changes in the investment and use of emission-intensive technologies. The run-up in gasoline prices in 2008 resulted in a shift in the composition of new cars and trucks sold toward more fuel-efficient vehicles, while reducing vehicle miles traveled by the existing fleet (Ramey and Vine, 2010). Likewise, electric utilities responded to the dramatic decline in natural gas prices (and decline in the relative gas-coal price) in 2009 and 2010 by dispatching more electricity from gas plants that resulted in lower carbon dioxide $\left(\mathrm{CO}_{2}\right)$ emissions and the lowest share of U.S. power generation by coal in some four decades (U.S. Energy Information Administration, 2009). Longer-term evaluations of the impacts of energy prices on markets have found that higher prices have induced more innovation - measured by frequency and importance of patents - and increased the commercial availability of more energy-efficient products, especially among energy-intensive goods such as air conditioners and water heaters (Newell, Jaffe, and Stavins, 1999; Popp, 2002).

\section{Cap-and-Trade Systems}

A cap-and-trade system constrains the aggregate emissions of regulated sources by creating a limited number of tradable emission allowances - in sum equal to the overall cap - and requiring those sources to surrender allowances to cover their emissions (Stavins, 2007). Faced with the choice of surrendering an allowance or reducing emissions, firms place a value on an allowance that reflects the cost of the emission reductions that can be avoided by surrendering an allowance. Regardless of the

initial allowance distribution, trading can lead allowances to be put to their highest-valued use: covering those emissions that are the most costly to reduce and providing the incentive to undertake the least costly reductions (Montgomery, 1972; Hahn and Stavins, 2012). 
In developing a cap-and-trade system, policymakers must decide on several elements of the system's design. Policymakers must determine how many allowances to issue - the size or level of the emission cap. Policymakers must determine the scope of the cap's coverage: identify the types of greenhouse gas emissions and sources covered by the cap, including whether to regulate upstream (based on carbon content of fuels) or downstream (based on monitored emissions).

After determining the amount of allowances and scope of coverage, policymakers must determine whether to freely distribute or sell (auction) allowances. Free allocation of allowances to firms could reflect some historical record ("grandfathering"), such as recent fossil fuel sales. Such grandfathering involves a transfer of wealth, equal to the value of the allowances, to existing firms, whereas, with an auction, this same wealth is transferred to the government. With an auction, the government would, in theory, collect revenue identical to that from a tax producing the same amount of emission abatement. As with tax receipts, auction revenues could be used to reduce distortionary taxes or finance other programs.

In an emission trading program, cost uncertainty - unexpectedly high or volatile allowance prices - can undermine political support for climate policy and discourage investment in new technologies and research and development. Therefore, attention has turned to incorporating "costcontainment" measures in cap-and-trade systems, including offsets, allowance banking and borrowing, safety valves, and price collars.

An offset provision allows regulated entities to offset some of their emissions with credits from emission reduction measures lying outside the cap-and-trade system's scope of coverage. An offset provision can link a cap-and-trade system with an emission-reduction-credit system (see below). Allowance banking and borrowing effectively permit emission trading across time. The flexibility to save an allowance for future use (banking) or to bring a future period allowance forward for current use (borrowing) can promote cost-effective abatement. Systems that allow banking and borrowing redefine the emission cap as a cap on cumulative emissions over a period of years, rather than a cap on annual emissions. This makes sense in the case of climate change, because it is a function of cumulative emissions of gases that remain in the atmosphere for decades to centuries.

A safety valve puts an upper bound on the costs that firms will incur to meet an emission cap by offering the option of purchasing additional allowances at a predetermined fee (the safety-valve "trigger price"). This effective price ceiling in the emission allowance market reflects a hybrid approach to climate policy: a cap-and-trade system that transitions to a tax in the presence of unexpectedly high mitigation costs. When firms exercise a safety valve, their aggregate emissions exceed the emission cap. A price collar combines the ceiling of a safety-valve with a price floor created by a minimum price in auction markets or a government commitment to purchase allowances at a specific price.

Increasing certainty about mitigation cost - through a carbon tax, safety valve or price collar reduces certainty about the quantity of emissions allowed. Smoothing allowance prices over time through banking and borrowing reduces the certainty over emissions in any given year, but maintains certainty of aggregate emissions over a longer time period. A cost-effective policy with a mechanism insuring against unexpectedly high costs - either through cap-and-trade or a carbon tax - increases the likelihood that firms will comply with their obligations and can facilitate a country's participation and compliance in a global climate agreement.

In a similar fashion as under a carbon tax, domestic cap-and-trade programs could include some variant of a border tax to mitigate some of the adverse competitiveness impacts of a unilateral domestic climate policy and encourage trade partners to take on mitigation policies with comparable stringency. 
In the case of a cap-and-trade regime, the border adjustment would take the form of an import allowance requirement, so that imports would face the same regulatory costs as domestically-produced goods. However, border measures under a carbon tax or cap-and-trade raise questions about the application of trade sanctions to encourage broader and more extensive emission mitigation actions globally, as well as questions about their legality under the World Trade Organization (Brainard and Sorking, 2009; Frankel, 2010).

\section{Emission-Reduction-Credit Systems}

An emission-reduction-credit (ERC) system delivers emission mitigation by awarding tradable credits for "certified" reductions. Generally, firms that are not covered by some set of regulations - be they command-and-control or market-based - may voluntarily participate in such systems, which serve as a source of credits that entities facing compliance obligations under the regulations may use.

For example, as we discuss below, the Clean Development Mechanism (CDM) under the Kyoto Protocol provides credits used by firms covered by the EU ETS. A firm earns credits for projects that reduce emissions relative to a hypothetical "no project" baseline. In determining the number of credits to grant a firm for a project, calculation of the appropriate baseline is therefore as important as measuring emissions. Dealing with this unobserved and fundamentally unobservable hypothetical baseline is at the heart of the so-called "additionality" problem.

While ERC systems can be self-standing, as in the case of the CDM, governments can also establish them as elements of domestic cap-and-trade or other regulatory systems. These ERC systems - often referred to as offset programs - serve as a source of credits that can be used by regulated entities to meet compliance obligations under the primary system. For example, the Regional Greenhouse Gas Initiative (RGGI) in the northeast United States, which regulates $\mathrm{CO}_{2}$ emissions from electric power plants (and which we discuss below), recognizes offsets from activities such as landfill methane capture and destruction, reductions in emissions of sulfur hexafluoride from the electric power sector, and afforestation. Electricity generators covered by RGGI can use these offset credits to cover part of their emissions. Other cap-and-trade systems that we discuss below also contain offset provisions.

\section{Clean Energy Standards}

The purpose of a clean energy standard is to establish a technology-oriented goal for the electricity sector that can be implemented cost-effectively (Aldy, 2011). Under such standards, power plants generating electricity with technologies that satisfy the standard create tradable credits that they can sell to power plants that fail to meet the standard, thereby minimizing the costs of meeting the standard's goal in a manner analogous to cap-and-trade.

In the United States, for example, state renewable electricity standards (RESs), a restricted type of a clean energy standard, typically establish the objective of the standard as a specific renewable share of total power generation that increases over time (U.S. Congressional Budget Office, 2011). A few states have implemented alternative energy standards in their power sector that target renewables, new nuclear power generating capacity, and advanced fossil fuel power generating technologies.

Clean energy standards that focus on technology targets do not explicitly price the greenhouse gas externality and thus impose a higher cost for a given amount of emission reductions than a carbon tax or cap-and-trade program. A renewable mandate treats coal-fired power, gas-fired power, and nuclear power as equivalent - none of these technologies create credits necessary for compliance - 
despite the fact that a natural gas combined cycle power plant typically produces a unit of generation with half the $\mathrm{CO}_{2}$ emissions of a conventional coal power plant, and a nuclear plant produces zeroemission power, as do wind, solar, and geothermal. Thus, mandating power from a limited portfolio of technologies can result in higher costs by providing no incentive to switch from emission-intensive coal to emission-lean gas or emission-free nuclear.

A more cost-effective approach to a clean energy standard would employ a technology-neutral performance standard, such as tons of $\mathrm{CO}_{2}$ per megawatt hour of generation. All power sources, from fossil fuels to renewables, could be eligible under such a performance standard. This has the advantage over the portfolio approach of providing better innovation incentives and of enabling all possible ways of reducing the emissions intensity of power generation. The Canadian province of Alberta has employed such a tradable carbon performance standard for most large sources of $\mathrm{CO}_{2}$ emissions and has required a 12\% improvement in the emission intensity of these sources since 2007.

Power plants would be awarded credits for generating cleaner (less emission-intensive) electricity than the standard. These clean power plants could sell credits to other power plants or save them for future use. Tradable credits promote cost-effectiveness by encouraging the greatest deployment of clean energy from those plants that can lower their emission intensity at lowest cost. Those power plants could then sell their extra credits to other power plants that face higher costs for deploying clean energy. The creation and sale of clean energy credits would provide a revenue stream that could conceivably enable the financing of low- and zero-emission power plant projects.

Eligible technologies for the standard could extend beyond generation technologies and also permit improvements in energy efficiency, or a broad set of emission offset activities, to create tradable credits. Extending the price on carbon to a broader set of activities could improve cost-effectiveness, but allowing for energy efficiency and other offsets poses risks. As emphasized above, estimating offsets is complex, requires extensive review and monitoring by third parties or regulatory agencies, and risks undermining the objective of a policy because of the additionality problem.

Monitoring and enforcement could be relatively straightforward under either a portfolio or performance standard approach. For example, in the United States, electricity generation, generating technology type, and $\mathrm{CO}_{2}$ emissions are already tracked at power plants by state and Federal regulators.

A clean energy standard represents a de facto free allocation of the right to emit greenhouse gases to the power sector. Suppose that the U.S. government created a clean energy performance standard of 0.5 tons of $\mathrm{CO}_{2}$ per megawatt hour (the 2010 U.S. power sector emission intensity was 0.56 tons of $\mathrm{CO}_{2} / \mathrm{MWh}$ ); this is roughly comparable to a $50 \%$ clean energy standard that allows all technologies with lower emission intensity than conventional coal to qualify (with partial crediting for low- but non-zero emitting facilities). As a result, a clean energy standard could not generate the revenues that a carbon tax or a cap-and-trade program with an allowance auction could.

\section{Eliminating Fossil Fuel Subsidies}

Phasing out fossil fuel subsidies can represent significant progress toward "getting prices right" for fossil fuel consumption, especially in some developing countries, where subsidies are particularly large. Imposing a carbon price on top of a fuel subsidy will not lead to the socially optimal price for the fuel, but removing such subsidies can deliver incentives for efficiency and fuel switching comparable to implementing an explicit carbon price. 
At the 2009 G20 Summit in Pittsburgh, Pennsylvania, the leaders of twenty of the largest developed and developing countries agreed to phase out fossil fuel subsidies over the "medium term," and encouraged all other nations to eliminate such subsidies. The agreement called for phasing out these subsidies while targeting support for the poor, and noted that "inefficient fossil fuel subsidies encourage wasteful consumption, reduce our energy security, impede investment in clean energy sources and undermine efforts to deal with the threat of climate change" (G20 Leaders, 2009). Soon thereafter, leaders of the APEC nations ${ }^{4}$ reached agreement on fossil fuel subsidy elimination at the 2009 Singapore Summit.

The economic and climate benefits of fossil fuel subsidy reform could be significant. In 2008, fossil fuel consumption subsidies exceeded $\$ 500$ billion globally. In at least ten countries, fossil fuel subsidies exceeded 5 percent of GDP, and constituted substantial fractions of government budgets (IEA, 2010). Eliminating fossil fuel subsidies could reduce global oil consumption by more than 4 million barrels per day, representing a decline of about 5 percent of current consumption. The International Energy Agency (2010) estimates that eliminating all fossil fuel subsidies would reduce global $\mathrm{CO}_{2}$ emissions by about 10 percent by 2020 .

Some developing country governments have been historically reticent to let fuel and electricity prices rise to market-determined levels because of concerns of public opposition. For example, protests over reducing petrol subsidies contributed to President Suharto's downfall in Indonesia in 1998 (Beaton and Lontoh, 2010). Interestingly, Indonesia successfully reduced their fossil fuel subsidies in 2005 by coupling the change in the fuel price regime with a targeted, means-tested program to transfer government resources from fuel subsidies to income support.

Critics of subsidy reform claim it will harm low-income households, but most fossil fuel subsidies disproportionately benefit the relatively wealthy in developing countries. Indeed, about 40 percent of the benefits of petroleum subsidies accrue to the wealthiest quintile, while the lowest income quintile enjoys less than 10 percent of the subsidy benefits, on average globally (Coady et al., 2010). ${ }^{5}$

To promote implementation and cooperation on the G20 fossil fuel subsidies commitment, the leaders established two processes that enable a de facto "pledge and review" process. First, the leaders tasked their energy and finance ministers to compile a list of their own country's fossil fuel subsidies and present their strategies for eliminating them. After a series of staff- and ministerial-level consultations among the G20, the energy and finance ministers presented their plans in 2010 (G20 Leaders, 2010a). Second, the leaders tasked the Organization of Economic Cooperation and Development (OECD), International Energy Agency (IEA), World Bank, and the Organization of Petroleum Exporting Countries (OPEC) to evaluate fossil fuel subsidies (G20 Leaders, 2009). These international organizations subsequently produced joint reports that serve as independent benchmarks of fossil pricing policies by which countries may evaluate others' subsidy elimination plans (IEA et al., 2010).

In 2010, the G20 leaders explicitly called on these international organizations to "further assess and review the progress made in implementing the Pittsburgh and Toronto commitments" (G20 Leaders, 2010b). While the $\mathrm{G} 20$ has no formal compliance mechanism to explicitly enforce the leaders'

\footnotetext{
4 The twenty-one "member economies" of APEC (Asia-Pacific Economic Cooperation) are: Australia, Brunei, Canada, Chile, China, Hong Kong, Indonesia, Japan, Korea, Malaysia, Mexico, New Zealand, Papua New Guinea, Peru, Philippines, Russia, Singapore, Taipei, Thailand, United States, and Viet Nam.

${ }^{5}$ The G20 agreement permits exclusion for subsidies that are explicitly targeted to low-income households. For example, the U.S. government has indicated that it considers the Low Income Home Energy Assistance Program to be exempt from subsidy elimination commitment for this reason.
} 
commitment, it does establish a goal, an implementation process, and what can effectively be a thirdparty expert review. This combination provides transparency for governments and stakeholders to assess whether nations are delivering on their leaders' commitments. This can promote credibility and trust for future international cooperation, and may provide some lessons for the design of bottom-up international climate policy (see more on this below in our discussion of international coordination of carbon pricing policies).

\section{Regional, National, and Sub-National Experiences with Carbon Pricing}

We briefly examine the few explicit carbon pricing policy regimes that are currently in place: the European Union's Emissions Trading Scheme; New Zealand's cap-and-trade system; the Kyoto Protocol's Clean Development Mechanism; northern European carbon tax policies; British Columbia's carbon tax; and Alberta's tradable carbon performance standard (similar to a clean energy standard). ${ }^{6}$

\section{European Union Emission Trading Scheme}

By far the world's largest carbon pricing regime is the European Union Emission Trading Scheme (EU ETS), a cap-and-trade system of $\mathrm{CO}_{2}$ allowances. Adopted in 2003 with a pilot phase that became active in 2005, the EU ETS covers about half of EU $\mathrm{CO}_{2}$ emissions in thirty countries in a region of the world that accounts for about 20 percent of global GDP and 17 percent of world energy-related $\mathrm{CO}_{2}$ emissions (Ellerman and Buchner, 2007). ${ }^{7}$ The 11,500 emitters regulated by the downstream program include large sources such as oil refineries, combustion installations over $20 \mathrm{MWth}$, coke ovens, cement factories, ferrous metal production, glass and ceramics production, and pulp and paper production. Up until now, the program has not covered sources in the transportation, commercial, or residential sectors (Ellerman and Buchner, 2007), although the EU plans to extend the ETS to cover aviation sector emissions starting in 2012.

The EU ETS was designed to be implemented in phases: a pilot or learning phase from 2005 to 2007, a Kyoto phase from 2008 to 2012, ${ }^{8}$ and a series of subsequent phases. Penalties for violations increase from 40 Euros per ton of $\mathrm{CO}_{2}$ in the first phase to 100 Euros in the second phase. Although the first phase allowed trading only in carbon dioxide, the second phase broadened the program to include other GHGs, such as nitrous oxide emissions.

The process for setting caps and allowances in member states was initially decentralized (Kruger, Oates, and Pizer, 2007), with each member state responsible for proposing its own national carbon cap, subject to review by the European Commission. This created incentives for individual countries to try to be generous with their allowances to protect their economic competitiveness (Convery and Redmond, 2007). Not surprisingly, the result was an aggregate cap that exceeded BAU emissions.

\footnotetext{
${ }^{6}$ In addition to the EU ETS and the New Zealand cap-and-trade system, the Japanese Voluntary Emissions Trading System has operated since 2006, and Norway operated its own emissions trading system for several years before joining the EU ETS in 2008. Legislation to establish cap-and-trade systems is under debate in Australia (combined with a carbon tax for an initial three-year period) and in the Canadian provinces of Ontario and Quebec. Japan is considering a compulsory emissions trading system.

${ }^{7}$ The EU ETS covers all 27 member states plus Iceland, Liechtenstein, and Norway.

${ }^{8}$ This is the first commitment period of the Kyoto Protocol, 2008-2012.
} 
In the spring of 2006, it became clear that the allocation of allowances in 2005 on net had exceeded emissions by about 4 percent of the overall cap. This led, as would be anticipated, to a dramatic fall in allowance prices. In January, 2005, the price per ton was approximately $€ 8 / \mathrm{tCO}_{2}$; by early 2006, it exceeded $€ 30 / \mathrm{tCO}_{2}$, then fell by about half in one week of April, 2006, before fluctuating and returning to about $€ 8 / \mathrm{tCO}_{2}$ (Convery and Redmond, 2007). This volatility was attributed to the absence of transparent, precise emissions data at the beginning of the program, a surplus of allowances, energy price volatility, and a program feature that prevents banking of allowances from the first phase to the second phase (Market Advisory Committee, 2007). In truth, the "over-allocation" was concentrated in a few countries, particularly in Eastern Europe, and in the non-power sectors (Ellerman and Buchner, 2007).

The first and second phases of the EU ETS require member states to distribute almost all of the emissions allowances (a minimum of 95 percent and 90 percent, respectively) freely to regulated sources, but beginning in 2013, member states will be allowed to auction larger shares of their allowances. The initial free distribution of allowances led to complaints from energy-intensive industrial firms about "windfall profits" among electricity generators, when energy prices increased significantly in 2005. But the higher electricity prices were only partly due to allowance prices, higher fuel prices also having played a role; and it is unclear whether the large profits reported by electricity generators were due mainly to their allowance holdings or to having low-cost nuclear or coal generation in areas where the (marginal) electricity price was set by higher-cost natural gas (Ellerman and Buchner, 2007).

The system's cap was tightened for Phase II (2008-2012), and its scope expanded to cover new sources in countries that participated in Phase I plus sources in Bulgaria and Romania, which acceded to the European Union in 2007. Liechtenstein, Iceland, and Norway joined the EU ETS in 2008, although sources in Iceland are not yet subject to an emissions cap. Allowance prices in Phase II increased to over $€ 20 / \mathrm{tCO}_{2}$ in the first half of 2008 , averaged $€ 22 / \mathrm{tCO}_{2}$ in the second half of 2008 , and then fell to $€ 13 / \mathrm{tCO}_{2}$ in the first half of 2009 , and down to $€ 10 / \mathrm{tCO}_{2}$ in the fall of 2011 , as the economic recession brought decreased demand for allowances due to reduced output in the energy-intensive sectors and lower electricity consumption.

The European Union plans to extend the EU ETS through Phase III, 2013-2020, with a centralized cap becoming increasingly stringent (20\% below 1990 emissions), a larger share of the allowances subject to auctioning, tighter limits on the use of offsets, and unlimited banking of allowances between Phases II and III.

\section{Regional Greenhouse Gas Initiative}

The Regional Greenhouse Gas Initiative (RGGI) is a downstream cap-and-trade program that was originally intended to limit $\mathrm{CO}_{2}$ emissions in the United States from power sector sources in ten northeastern states (Connecticut, Delaware, Maine, Maryland, Massachusetts, New Hampshire, New Jersey, ${ }^{9}$ New York, Rhode Island, and Vermont). ${ }^{10}$ The system is both narrow in its sectoral coverage and unambitious in terms of its emissions reduction objectives.

\footnotetext{
${ }^{9}$ In May of 2011, New Jersey Governor Chris Christie announced that his state would withdraw from the system.

${ }^{10}$ In addition to RGGI, other regional and state efforts to limit GHGs in the United States have begun. One of the most prominent is California's enactment of the Global Warming Solutions Act of 2006, which set a state-wide GHG emissions limit for 2020 equal to California's 1990 emissions level. In 2008, the California Air Resources Board proposed the use of a cap-and-trade program as a primary policy for achieving this target. The cap initially would cover electric generators and large industrial facilities, and its scope would later be expanded to include smaller facilities and the transportation sector. The cap-and-trade system is scheduled to commence operations in 2012.
} 
The program took effect in 2009, after approval by individual state legislatures, and set a goal of limiting emissions from regulated sources to then current levels in the period from 2009 to 2014. Beginning in 2015, the emissions cap is set to decrease by 2.5 percent each year until it reaches an ultimate level 10 percent below 2009 emissions in 2019. It was originally anticipated that meeting this goal would require a reduction approximately 35 percent below business-as-usual emissions (13 percent below 1990 emissions levels). However, due the combined effects of the economic recession and drastic declines in natural gas prices relative to coal prices, the program is no longer binding and is unlikely to become binding through 2020, unless the targets are revised. ${ }^{11}$

Because RGGI only limits emissions from the power sector, incremental monitoring costs are low, because U.S. power plants are already required to report their hourly $\mathrm{CO}_{2}$ emissions to the Federal government (under provisions for continuous emissions monitoring as part of the $\mathrm{SO}_{2}$ allowance trading program). The system sets standards for certain categories of $\mathrm{CO}_{2}$ offsets, and limits the number and geographic distribution of offsets. The program requires participating states to auction at least 25 percent of their allowances and to use the proceeds for energy efficiency and consumer-related improvements. ${ }^{12}$ The remaining 75 percent of allowances may be auctioned or distributed freely. In practice, states have auctioned virtually all allowances.

Several problems with the program's design can be noted. First is the leakage problem, which is potentially severe for any state or regional program, particularly given the inter-connected nature of electricity markets (Burtraw, Kahn, and Palmer, 2005). Second, the program is downstream for just one sector of the economy, and so very limited in scope. Third, despite considerable cost uncertainty, a true firm safety-valve mechanism was not adopted. Instead, there are trigger price that allow greater reliance on offsets and external credits in the expectation that these can increase supply. The program does impose a price floor in the allowance auctions, without which the allowance prices would have approached zero (when the combined forces of the economic recession and lower natural gas prices caused emissions to fall below the declining cap). Fourth, as mentioned above, the program limits the number and geographic origin of offsets.

\section{New Zealand Emissions Trading Scheme}

In January, 2008, the New Zealand Emissions Trading Scheme (NZ ETS) was launched. Under this system, the intention is to include all sectors of the economy and all greenhouse gases by 2015, using free allocation of allowances, with special protections (output-based updating allocations) for emission-intensive, trade-sensitive sectors. The forestry sector entered the program first, in 2008; and stationary energy, industrial, and liquid fuel fossil fuel sectors joined in 2010. The waste (landfills) sector is scheduled to enter in 2013, and agriculture - which accounts for nearly half of New Zealand's gross emissions - is scheduled to enter in $2015 .{ }^{13}$

Covered sources have the option of paying a fixed fee of NZ\$25 per ton of emissions, and until 2013 , all sectors other than forestry require only one unit of allowances for each two units of emissions.

\footnotetext{
${ }^{11}$ Allowance prices have reflected these realities, falling from approximately $\$ 3$ per ton of $\mathrm{CO}_{2}$ at the first auction in September, 2008, to the floor price of \$1.89 per ton in 2011.

${ }^{12}$ Three states have used some of their auction revenue to help balance their overall state budgets.

${ }^{13}$ See: http://www.climatechange.govt.nz/emissions-trading-scheme/
} 
Thus, although the NZ allowances are indirectly linked with the EU ETS through the CDM, the current effective price is very low while the system becomes established. Early evidence suggests that the forestry component has deterred deforestation and may be encouraging new planting, although international policy and consequent price uncertainty are major problems for investment (Karpas and Kerr, 2010).

The Climate Change Response Act of 2002, which provided for the creation of the emissions trading scheme for the purpose of meeting the country's Kyoto obligations, required a review of the NZ ETS by an independent review panel every five years. The first review (Emissions Trading Scheme Review Panel, 2011) was released by the government in September, 2011. While most of the scheme was upheld, it recommended that the agriculture sector face a lower price as it enters the system, and that the government should review the wisdom of allowing offsets from HFC-23 destruction projects under the Clean Development Mechanism (see below). The government hopes to link with Australia's emissions trading program, scheduled to be launched in 2015.

\section{Clean Development Mechanism}

The most significant GHG emission-reduction-credit system to date is the Kyoto Protocol's Clean Development Mechanism (CDM). Under the CDM, certified emission reduction (CER) credits are awarded for voluntary emission reduction projects in non-Annex I countries (largely, developing countries) that ratified the Protocol, but are not among the Annex I countries subject to the Protocol's emission limitation commitments - also known as the Annex B countries. ${ }^{14}$ While CERs can be used by the Annex I countries to meet their emission commitments, they could also be used for compliance purposes by entities covered by other cap-and-trade systems, including systems in countries that are not Parties to the Protocol, such as the United States.

From the perspective of the industrialized countries, the CDM provides a means to engage developing countries in the control of GHG emissions, while from the perspective of the developing countries, the CDM provides an avenue for the financing of "sustainable development." Essentially, the purchase of CERs by industrialized country entities to offset their own emissions can reduce the aggregate cost of compliance with the Kyoto Protocol, because it tends to be much less expensive to construct new low-carbon energy infrastructure in developing nations than to modify or replace existing infrastructure in industrialized countries (Wara, 2007).

Of the six GHGs covered by the Kyoto Protocol, ${ }^{15}$ approximately $38 \%$ of projects in the CDM pipeline as of 2007 were for $\mathrm{CO}_{2}, 28 \%$ for HFC-23, 23\% for methane, and $11 \%$ for nitrous oxide (Wara, 2007). In terms of $\mathrm{CO}_{2}$-equivalent reductions, the $\mathrm{CDM}$ has accounted for annual reductions of 278 million tons, about 1 percent of annual global emissions of $\mathrm{CO}_{2}$ (U.S. Energy Information Administration, 2011). ${ }^{16}$ The largest shares of CERs have been generated in China (52\%) and India (16\%), with Latin

\footnotetext{
${ }^{14}$ Parties include thirty-seven industrialized countries and emerging market economies of central and eastern Europe. Like the CDM, Joint Implementation (JI) was established as a project-based flexibility mechanism under the Kyoto Protocol. Unlike the CDM, Jl applies to emission reduction projects carried out in an Annex I country (the host country) that has a national emissions target under the Protocol. Jl projects generate credits, referred to as emission reduction units (ERUs), which can be used to cover increased emissions in other countries.

${ }^{15}$ These are: $\mathrm{CO}_{2}$, methane, nitrous oxide, hydrofluorocarbons, perfluorocarbons, and sulfur hexafluoride.

${ }^{16}$ Note that carbon sequestration projects of forestation and reduced deforestation are not included in the CDM under the Kyoto Protocol's first commitment period, 2008-2012.
} 
America and the Caribbean making up another $15 \%$ of the total, Brazil (at 7\%) being the largest producer in that region (World Bank, 2010).

Because the CDM is an ERC system, it is subject to concerns about the additionality of emissionreductions associated with its projects (see generic discussion above regarding ERC systems). Empirical analysis has validated these concerns, with estimates that up to $75 \%$ of claimed reductions would have occurred in the absence of the program (Zhang and Wang, 2011).

A particular concern has centered on the fact that nearly $30 \%$ of average annual CERs have come from the destruction of HFC-23, a potent GHG that is a by-product of the manufacture of certain refrigerant gases. It is very inexpensive to destroy HFC-23, and companies can earn nearly twice as much from sale of CDM credits as they can from selling respective refrigerant gases. As a result, it has been argued that plants are being built simply for the purpose of generating CERs from destruction of HFC-23. Because of this, beginning in 2013, CERs from HFC-23 destruction will not be valid for purposes of compliance with the EU ETS.

As debate continues regarding a possible second commitment period for the Kyoto Protocol, it appears that the CDM will continue to function, in any event (Bodansky, 2011). A variety of proposals have been put forward to improve its structure and implementation, many targeted at increasing the additionality of approved projects (Hall, Levi, Pizer, and Ueno, 2010). In the meantime, as we discuss below, the CDM may provide a significant function by facilitating indirect linkages among diverse national cap-and-trade systems.

\section{Northern European Experience with Carbon Taxes ${ }^{17}$}

In the 1990s, a number of northern European countries imposed carbon taxes to limit their greenhouse gas emissions. In 1991, Norway implemented a carbon tax that varied in its level across sectors of the economy, despite the fact that cost-effective abatement would call for a uniform tax. In the transportation sector, by 2009, the Norwegian carbon tax had increased to about $\$ 58 / \mathrm{tCO}_{2}$ on gasoline, but only $\$ 34 / \mathrm{tCO}_{2}$ on diesel (Government of Norway, 2009). Natural gas faced a carbon tax of $\$ 31 / \mathrm{tCO}_{2}$ to $\$ 33 / \mathrm{tCO}_{2}$ in 2009 , depending on use. By 1999 , facilities using coal paid $\$ 24 / \mathrm{tCO}$ for coal for energy purposes and $\$ 19 / \mathrm{tCO}_{2}$ for coal for coking purposes (Bruvoll and Larsen, 2004), but the Government of Norway exempted these activities from the carbon tax starting in 2003 (Government of Norway, 2009). In 2009, the carbon tax applied to about 55 percent of Norwegian greenhouse gas emissions, while the emission trading scheme that is linked to the EU ETS covered an additional 13 percent of emissions. ${ }^{18}$ In 2003, Norway also introduced a tax of about $\$ 33 / \mathrm{tCO}_{2}$-equivalent on HFCs and PFCs, which slowed the growth rate of these potent greenhouse gases (Government of Norway, 2009).

Likewise in 1991, Sweden implemented a carbon tax of about $\$ 33 / \mathrm{tCO}_{2}$ as a part of a fiscal reform that lowered high income tax rates (Speck, 2008). The carbon tax has since increased to more than $\$ 135 / \mathrm{tCO}_{2}$ by 2009 (Government of Sweden, 2009). At the same time, Sweden reduced its general energy tax on many of the sources bearing the carbon tax. Refineries, steel, and other primary metal industries received an exemption from the carbon tax (Daugjberg and Pedersen 2004). In addition, those industries covered by the EU ETS were exempted from the carbon tax (Government of Sweden,

\footnotetext{
${ }^{17}$ All carbon taxes reported in this subsection are in 2009 U.S. dollars, based on market exchange rates.

${ }^{18}$ Greenhouse gas emissions in the offshore oil sector, representing 24 percent of the nation's emissions, are covered by both a (lower) carbon tax and the emission trading scheme (Government of Norway, 2009).
} 
2009). About 33 percent of Sweden's greenhouse gas emissions are covered by the EU ETS, a smaller fraction than the norm in the EU (Government of Sweden, 2009).

In 1992, Denmark implemented a carbon tax of about $\$ 18 / \mathrm{tCO}_{2}$, and reduced this tax modestly to a level of about $\$ 17 / \mathrm{tCO}_{2}$ in 2005, where it remained through 2009 (Speck, 2008; Government of Denmark, 2009). Manufacturing industries bear discounted tax rates of more than 90 percent depending on their energy intensity and participation in a voluntary agreement (Government of Denmark, 2009). The carbon tax on gasoline amounted to about 16 cents per gallon in 2009.

Since 1997, Finland has imposed a general tax on energy coupled with a surtax based on the carbon content of the energy. Like other northern European nations, Finland reduced its carbon tax for some industries covered by the EU ETS, reflecting concerns about adverse competitiveness impacts on trade-exposed manufacturing. Since 2008 , the carbon surtax has been about $\$ 28 / \mathrm{tCO}_{2}$, although natural gas faces half this rate (Government of Finland, 2009).

Obviously, implementation of carbon taxes in northern Europe have yielded significant variations in the effective tax per unit $\mathrm{CO}_{2}$ across fuels and industries within each country, contrary to the cost-effective prescription of a common price on carbon among all sources. In addition, fiscal cushioning to carbon taxes - by adjustments to pre-existing energy taxes - and to the EU ETS - by adjustments to then pre-existing carbon taxes - was common, especially for those industries expressing concerns about their international competitiveness. Nonetheless, these nations have demonstrated that carbon taxes can deliver greenhouse gas emission reductions and raise revenues to finance government spending and lower income tax rates.

\section{British Columbia Carbon Tax}

Since 2008, the Canadian province of British Columbia has had in place a carbon tax as one part of its plan to reduce provincial GHG emissions by 33 percent by 2020 (British Columbia 2007). The carbon tax is intended to be economy-wide, with a tax of $\mathrm{C} \$ 10$ per ton of $\mathrm{CO}_{2}$-equivalent emissions in 2008 , increasing by $\mathrm{C} \$ 5$ per year for four years, and reaching $\mathrm{C} \$ 30 /$ ton in 2012 . The tax is collected "upstream" at the wholesale level (fuel distributors) based on the carbon content of fuels to facilitate administration (Duff, 2008). By law, 100\% of the tax revenue must be refunded through tax cuts to businesses and individuals, and low-income individuals are further protected through a Low Income Climate Action Tax Credit.

During 2008 and 2009, the tax generated $\$ 846$ million in revenue. This was accompanied by reductions in a variety of personal and corporate income taxes, plus tax credits for low-income individuals. These cuts totaled approximately $\$ 1.1$ billion, so that the policy yielded significant net tax reductions (Plumer, 2010). A similar pattern occurred in 2010. The government estimates that by 2020, the carbon tax will reduce British Columbia's $\mathrm{CO}_{2}$ emissions by approximately 3 million tons annually.

Interestingly, another part of the province's Climate Action Plan is a provincial cap-and-trade system, which is to be linked with a similar systems planned in California (under Assembly Bill 32), Ontario, and Quebec through the Western Climate Initiative. The province's plans have not addressed how the carbon tax and cap-and-trade system will be coordinated. ${ }^{19}$

\footnotetext{
${ }^{19}$ An important issue for national and sub-national climate policies is the potential for interactions - some problematic and some positive - among overlapping policy instruments. On this, see: McGuinness and Ellerman, 2008; Fischer and Preonas, 2010; Levinson, 2010; Goulder and Stavins, 2011; and Organization for Economic Cooperation and Development, 2011.
} 


\section{Alberta Tradable Carbon Performance Standard}

In 2007, the Canadian province of Alberta designed a market-based policy to reduce the carbon intensity of its large sources of greenhouse gas emissions. This program established a rate-based performance standard for emission sources exceeding 100,000 metric tons of $\mathrm{CO}_{2}$ annually. Building on emission inventories dating to 2003 , each large source covered by the program was required to reduce the emission intensity of its production 12 percent below a base year intensity drawn from the 20032006 period. ${ }^{20}$ The program covers about 100 sources from the power sector, pulp and paper, cement, and fertilizer industries, and oil sands development. The unit of measure is emissions of $\mathrm{CO}_{2}$ per unit of physical production from that industry, for example, per barrel of oil from oil sands development (Sass, 2010).

Covered firms have four options for complying with the performance standard. First, they can reduce the emission intensity of production to meet the standard. Second, they may purchase credits from other covered firms with emission intensities below the standard. Third, they may purchase Alberta-based emission offset credits through an emission-reduction credit program. Finally, they may pay the provincial government $\$ 15$ for every metric ton they exceed the standard by, which serves as a safety valve on the cost of compliance with the program (Province of Alberta 2008).

In 2010, covered sources employed all four options to comply with the performance standard. These sources reduced their emissions relative to baseline by about 2.7 million tons of $\mathrm{CO}_{2}$ (with a majority of this effort traded from low mitigation cost facilities to high mitigation cost facilities), purchased about 3.9 million tons emission offset credits, and satisfied the remaining 4.7 million ton emission reduction obligation through the $\$ 15 / \mathrm{tCO}_{2}$ safety valve. This last option generated about $\$ 70$ million of revenue directed to the Climate Change and Emissions Management Fund, which invests in emission-lean technologies and projects (Province of Alberta 2011).

\section{International Coordination of Carbon Pricing Policies}

Climate change is truly a global commons problem: the location of greenhouse gas emissions has no effect on the global distribution of damages. Hence, free-riding problems plague unilateral and multilateral approaches. Further, nations will not benefit proportionately from greenhouse gas mitigation policies. Thus, mitigation costs are likely to exceed direct benefits for virtually all countries. Cost-effective international policies - insuring that countries get the most environmental benefit out of their mitigation investments - will help promote participation in an international climate policy regime.

In principle, internationally-employed market-based instruments can achieve overall cost effectiveness. Three basic routes stand out. First, countries could agree to apply the same tax on carbon (harmonized domestic taxes) or adopt a uniform international tax. Second, the international policy community could establish a system of international tradable permits, - effectively a nation-state level cap-and-trade program. In its simplest form, this represents the Kyoto Protocol's Annex B emission targets and the Article 17 trading mechanism. Third, a more decentralized system of internationallylinked domestic cap-and-trade programs could ensure internationally cost-effective emission mitigation.

\footnotetext{
${ }^{20}$ New sources covered by the program initially bear less stringent performance standards that converge to the 12 percent objective over time (Province of Alberta, 2007).
} 


\section{International Taxes and Harmonized Domestic Taxes}

In principle, a carbon tax could be imposed on nation states by an international agency. The supporting agreement would have to specify both tax rates and a formula for allocating the tax revenues. Cost-effectiveness would require a uniform tax rate across all countries. It is unclear, however, what international agency could impose and enforce such a tax, and so an alternative more frequently considered has been a set of harmonized domestic carbon taxes (Cooper, 2010). In this case, an agreement would stipulate that all countries are to levy the same domestic carbon taxes and retain their revenues.

The uniformity of tax rates is necessary for cost-effectiveness. But some developing countries may argue that the resulting distribution of costs does not conform to principles of distributional equity and call for significant resource transfers. Under a harmonized tax system, an agreement could include fixed lump-sum payments from developed to developing countries, and under an international tax system, an agreement could specify shares of the total international tax revenues that go to participating countries.

As an alternative to these explicit transfers, developed countries could commit to constrain the use of their tax revenues in ways that produce global benefits. For example, carbon tax revenues in developed countries could, in part, finance major research and development programs on zero-carbon technologies and adaptation efforts in developing countries, while developing countries could freely use their tax revenues in ways that best facilitate their development.

In some developing countries reluctant to implement a carbon tax, an initial cost-effective contribution to combat climate change could take the form of reducing fossil fuel subsidies. For example, a developing country cutting a petrol subsidy equal to 10 percent of its price is approximately equivalent to a rich country imposing a carbon tax on petrol that raises its price 10 percent. Wellplanned, broad fossil fuel price reforms in a developing country could deliver substantial emission mitigation just as a carbon tax in a developed country (IEA 2010). The energy prices are higher in both countries, providing the incentive to invest in energy-efficient technologies and non-fossil energy sources, but the relative prices remain unchanged, so that energy-intensive firms do not face the incentive to relocate to the developing country.

Lowering energy subsidies can free up government revenues that could be directed to other beneficial uses and improve the allocation of resources in the economy to promote faster economic growth. Of course, some energy subsidies in developing countries address pressing, basic energy needs, and efforts to combat climate change may need to account for these social objectives.

\section{International Tradable Permits: Cap-and-Trade and Emission-Reduction-Credits}

Under an international tradable permit scheme, all participating countries would be allocated permits for "net emissions," that is, emissions minus sequestration. A permit would define a right to emit a given volume over some time period, such as a year. In each period, countries would be free to buy and sell permits on an international exchange.

Initial permit allocations could reflect a variety of criteria, such as previous emissions, gross domestic product, population, and fossil fuel production. Whatever the initial allocation, subsequent trading can, in theory, lead to a cost-effective outcome (Montgomery, 1972), if transaction costs are not significant (Stavins, 1995). This potential for pursuing distributional objectives while assuring costeffectiveness is an important attribute of the tradable permit approach. 
Providing large initial permits to developing countries (for reasons of distributional equity) implies that they would sell permits primarily to developed countries. Since permit prices represent an implicit tax on all participating countries, the terms of trade within the coalition for countries with the same carbon intensities in production would remain unaffected. From a distributional point of view, developing countries would receive compensation, whereas developed countries would have to pay for their own emission abatement and for permit purchases from abroad to cover the balance of their emissions (Olmstead and Stavins, 2012).

An important obstacle to the successful operation of such a system is that by its very nature, the trading would be among nations (Hahn and Stavins, 1999). Nation-states are hardly simple costminimizers, like private firms, so there is no reason to anticipate that competitive pressures would lead to equating of marginal abatement costs across countries. The system would not have the costeffectiveness property ordinarily associated with a domestic tradable permit system among firms. Even if nations were cost-minimizers, they do not have sufficient information about the marginal abatement costs of firms within their jurisdiction to define their own aggregate marginal costs. The notion of a simple trading program among countries may be more of a metaphor than a practical policy.

If every country participating in such a system were to devolve the tradable permits to firms within its jurisdiction, that is, if each country instituted a domestic tradable permit system as its means of achieving its national target, then the trading could be among firms, not governments, both within countries and internationally (Hahn and Stavins, 1999). Such a system could indeed be cost-effective. In the near term, this trading system could be integrated with an emission-reduction-credit system, such as the CDM, for countries that do not take on emission caps.

The current design of the CDM does not secure all low-cost mitigation opportunities in developing countries. The project basis for credits under the CDM increases transaction costs and excludes policy reforms that undermine the cost-effectiveness of the mechanism. Modifying the CDM along several lines could improve its cost-effectiveness, increase the investment in low-carbon technologies in developing countries, and address concerns about whether CDM activities truly reflect additional emission mitigation effort (Hall, Levi, Pizer, and Ueno, 2010).

First, the CDM could be expanded to cover mitigation policies. Some of the potentially lowhanging fruit in developing countries - from reducing energy subsidies to designing and enforcing building codes - do not neatly fall within a "project" under the CDM. A policy-oriented CDM could deliver price signals to a greater share of a developing country's economy that can yield more emission mitigation and reduce the potential for emission leakage. This could also serve as a mechanism for transfers to developing countries that pursue a carbon tax. The obvious challenge lies in setting baseline emissions in order to assess the emission reduction benefits for any given policy. This effort may be substantial, but when spread over all of the potential emission reductions, the transaction costs may be minor in comparison to the costs of a project-based approach resulting in the same abatement.

Second, the CDM could be expanded to cover sectors as an alternative to projects. A sectoral CDM could establish emission baselines for entire sectors (such as the power sector or the steel sector), and allow countries to implement mitigation policies in those sectors to generate credits. Integrating these policies into the international regime - such as pegging a sectoral carbon tax to the international tradable permit price, or implementing a sectoral cap-and-trade system linked to the international regime - could promote cost-effectiveness. Focusing on the most energy-intensive sectors could also address concerns about competitiveness and emission leakage in developed countries. It would also 
provide developing countries with the experience to inform their consideration of taking on broader emission or policy commitments in future agreements. ${ }^{21}$

\section{Decentralized, Bottom-Up Architectures}

Cap-and-trade systems seem to have emerged as the preferred national and regional instrument for reducing emissions of greenhouse gases throughout much of the industrialized world, and the CDM has developed a substantial constituency, despite concerns about its performance. Because linkage between tradable permit systems (that is, unilateral or bilateral recognition of allowances from one system for use in another) can reduce compliance costs and improve market liquidity, there is great interest in linking cap-and-trade systems with each other.

There are not only benefits but also concerns associated with various types of linkages (Jaffe, Ranson, and Stavins, 2010). A major concern is that when two cap-and-trade systems are directly linked (that is, allow bilateral recognition of allowances in the two jurisdictions), key cost-containment mechanisms, such as safety-valves, are automatically propagated from one system to the other. Because some jurisdictions (such as the European Union) are opposed to the notion of a safety valve, whereas other jurisdictions (such as the United States) seem very favorably predisposed to the use of a safety valve, challenging harmonization would be required.

This problem can be avoided by the use of indirect linkage, whereby two cap-and-trade systems accept offsets from a common emission-reduction-credit system, such as the Clean Development Mechanism. As a result, the allowance prices of the two cap-and-trade systems converge (as long as the ERC market is sufficiently deep), and all the benefits of direct linkage are achieved (lower aggregate cost, reduced market power, decreased price volatility), but without the propagation from one system to another of cost-containment mechanisms. Such indirect linkage may already be evolving as a key element of the de facto post-2012 international climate policy architecture.

Despite the apparent current popularity of cap-and-trade as a national policy approach in many parts of the world, in reality, there are a variety of policy instruments - both market-based and conventional command-and-control - that countries can employ to reduce their GHG emissions. Hence, it is important to ask whether a diverse set of heterogeneous national, sub-national, or regional climate policy instruments can be linked in productive ways. The basic answer is that such a set of instruments can be linked, but the linkage is considerably more difficult than it is with a set of more homogeneous tradable permit systems (Hahn and Stavins, 1999). In fact, the basic approach behind emission reduction credit systems such as the CDM and Joint Implementation (JI) can be extended to foster linkage opportunities among diverse policy instruments, including cap-and-trade, taxes, and certain regulatory systems (Metcalf and Weisbach, 2010).

Another form of coordination can be unilateral instruments of economic protection, that is, border adjustments. In the case of a national carbon tax, this would take the form of a tax on imports that was equivalent to the implicit tax on the same domestically produced goods. In the case of a cap-

\footnotetext{
${ }^{21}$ Such an approach could be superior to some calls for sectoral policies that effectively set industry-specific performance standards common across participating developed and developing countries. This standard approach establishes walls between sectors that can increase the total mitigation cost for any given emission goal and eliminates opportunities to raise revenues, either through a carbon tax or an allowance auction, to benefit other social objectives.
} 
and-trade system, this would take the form of an import-allowance-requirement. Such border adjustments are found as part of most existing, planned, and proposed national climate policies.

\section{The Future of Carbon Pricing}

The political responses to possible market-based approaches to climate policy in most countries have been and will continue to be largely a function of issues and structural factors that transcend the scope of environmental and climate policy. Because a truly meaningful climate policy - whether market-based or conventional in design - will have significant impacts on economic activity in a wide variety of sectors (because of the pervasiveness of energy use in a modern economy) and in every region of a country, it is not surprising that proposals for such policies bring forth significant opposition, particularly during difficult economic times.

In the United States, political polarization - which began some four decades ago, and accelerated during the economic downturn - has decimated what had long been the key political constituency in the Congress for environmental (and energy) action, namely, the middle, including both moderate Republicans and moderate Democrats (Stavins, 2011). Whereas Congressional debates about environmental and energy policy had long featured regional politics, they are now fully and simply partisan. In this political maelstrom, the failure of cap-and-trade climate policy in the U.S. Senate in 2010 was essentially collateral damage in a much larger political war.

It is possible that better economic times will reduce the pace - if not the direction - of political polarization. Furthermore, it is also possible that the ongoing challenge of large budgetary deficits in many countries will increase the political feasibility of new sources of revenue. When and if this happens, consumption taxes (as opposed to traditional taxes on income and investment) could receive heightened attention, and primary among these might be energy taxes, which can be significant climate policy instruments, depending upon their design.

It is much too soon to speculate on what the future will hold for the use of market-based policy instruments for climate change. It is conceivable that two decades of relatively high receptivity in the United States, Europe, and other parts of the world to cap-and-trade and offset mechanisms will turn out to be no more than a relatively brief departure from a long-term trend of reliance on conventional means of regulation. On the other hand, it is also possible that the recent tarnishing of cap-and-trade in U.S. political dialogue will itself turn out to be a temporary departure from a long-term trend of increasing reliance on market-based environmental policy instruments. It is too soon to say.

\section{REFERENCES}

Aldy, Joseph E. (2011). "Promoting Clean Energy in the American Power Sector," The Hamilton Project Discussion Paper 2011-04.

Aldy, Joseph E. and William A. Pizer. (2009). "Competitiveness Impacts of Climate Change Mitigation Policies." Arlington, VA: Pew Center on Global Climate Change, May.

Beaton, Christopher and Lucky Lontoh. (2010). "Lessons Learned from Indonesia's Attempts to Reform Fossil-Fuel Subsidies." International Institute for Sustainable Development, Winnipeg, Canada. 
Bodansky, Daniel. (2011). "W[h]ither the Kyoto Protocol? Durban and Beyond." Policy Brief, Harvard Project on Climate Agreements, Belfer Center for Science and International Affairs, Harvard Kennedy School.

Brainard, Lael, and Isaac Sorking, eds. (2009). Climate Change, Trade, and Competitiveness: Is a Collision Inevitable? Brookings Institution Press.

British Columbia. (2007). Climate Action Plan. Vancouver, Canada.

Bruvoll, Annegrete and Bodil Merethe Larsen. (2004). "Greenhouse Gas Emissions in Norway: Do Carbon Taxes Work?” Energy Policy 32: 493-505.

Burtraw, Dallas, Danny Kahn, and Karen Palmer. (2005). " $\mathrm{CO}_{2}$ Allowance Allocation in the Regional Greenhouse Gas Initiative and the Effect on Electricity Investors." Discussion Paper CP 05-55. Washington, D.C.: Resources for the Future.

Carlson, Curtis, Dallas Burtraw, Maureen Cropper, and Karen Palmer. (2000). " $\mathrm{SO}_{2}$ Control by Electric Utilities: What Are the Gains from Trade?" Journal of Political Economy 108: 1292-326.

Coady, David, Robert Gillingham, Rolando Ossowski, John Pietrowski, Shamsuddin Tareq, and Justin Tyson. (2010). Petroleum Product Subsidies: Costly, Inequitable, and Rising. IMF Staff Position Note SPN/10/05. Washington, DC: International Monetary Fund.

Convery, Frank, and Luke Redmond. (2007). "Market and Price Developments in the European Union Emissions Trading Scheme." Review of Environmental Economics and Policy 1:66-87.

Cooper, Richard N. (2010). "The Case for Charges on Greenhouse Gas Emissions." Joseph E. Aldy and Robert N. Stavins, eds., Post-Kyoto International Climate Policy: Implementing Architectures for Agreement, pp. 151-178. New York: Cambridge University Press.

Daugjberg, Cartsen and Anders Branth Pedersen. (2004). "New Policy Ideas and Old Policy Networks: Implementing Green Taxation in Scandinavia." Journal of Public Policy 24(2): 219-249.

Duff, David G. (2008). "Carbon Taxation in British Columbia." Vermont Journal of Environmental Law 10: 85-105.

Ellerman, A. Denny, and Barbara K. Buchner. (2007). "The European Union Emissions Trading Scheme: Origins, Allocation, and Early Results." Review of Environmental Economics and Policy, volume 1 , number 1 , pp. 66-87.

Emissions Trading Scheme Review Panel. (2011). Doing New Zealand's Fair Share: Emissions Trading Scheme Review 2011, Final Report. Wellington: Ministry for the Environment.

Fischer, Carolyn, and Louis Preonas. (2010). "Combining Policies for Renewable Energy: Is the Whole Less than the Sum of Its Parts?" International Review of Environmental and Resource Economics, $4(1)$, pp. 51-92. 
Frankel, Jeffrey. (2010). "Global Environment and Trade Policy," in Joseph E. Aldy and Robert N. Stavins, eds., Post-Kyoto International Climate Policy: Implementing Architectures for Agreement, pp. 493-529. New York: Cambridge University Press.

G20 Leaders. (2009). Leaders' Statement: The Pittsburgh Summit. September 24-25, 2009.

G20 Leaders. (2010a). Annex: G20 Initiative on Rationalizing and Phasing Out Inefficient Fossil Fuel Subsidies, Implementation Strategies and Timetables. Toronto G20 Summit, June 2010.

G20 Leaders. (2010b). The G20 Seoul Summit Leaders' Declaration. November 11-12, 2010.

Goulder, Lawrence H. (1995). “Environmental Taxation and the 'Double Dividend': A Reader's Guide.” International Tax and Public Finance 2(2).

Goulder, Lawrence H. and lan W.H. Parry. (2008). "Instrument Choice in Environmental Policy." Review of Environmental Economics and Policy, volume 2, number 2, pp. 152-174.

Goulder, Lawrence H., and Robert N. Stavins. (2011). "Challenges from State-Federal Interactions in U.S. Climate Change Policy." American Economic Review Papers and Proceedings 101:3, pp. 253257.

Government of Denmark. (2009). Denmark's Fifth National Communication on Climate Change. Ministry of Climate and Energy, Copenhagen.

Government of Finland. (2009). Finland's Fifth National Communication under the Framework Convention on Climate Change. Ministry of the Environment and Statistics Finland, Helsinki.

Government of Norway. (2009). Norway's Fifth National Communication under the Framework Convention on Climate Change. Norwegian Ministry of the Environment, Oslo.

Government of Sweden. (2009). Sweden's Fifth National Communication on Climate Change. Ministry of the Environment, Stockholm.

Hahn, Robert W., and Robert N. Stavins. (1999). What Has the Kyoto Protocol Wrought? The Real Architecture of International Tradeable Permit Markets. Washington, D.C.: The AEI Press.

Hahn, Robert W., and Robert N. Stavins. (2012). "The Effect of Allowance Allocations on Cap-and-Trade System Performance." The Journal of Law and Economics, forthcoming.

Hall, Daniel S., Michael A. Levi, William A. Pizer, and Takahiro Ueno. (2010). "Policies for Developing Country Engagement." Joseph E. Aldy and Robert N. Stavins, eds., Post-Kyoto International Climate Policy: Implementing Architectures for Agreement, pp. 649-681. New York: Cambridge University Press.

International Energy Agency (IEA). (2010_. World Energy Outlook 2010. Paris: IEA. 
IEA, OPEC, OECD, and World Bank. (2010). Analysis of the Scope of Energy Subsidies and Suggestions for the G20 Initiative. Prepared for submission to the G-20 Summit Meeting, Toronto, Canada, June 26-27, 2010. June 16 Version.

Interagency Working Group on Social Cost of Carbon, United States Government. (2010). Technical Support Document: Social Cost of Carbon for Regulatory Impact Analysis Under Executive Order 12866.

Jaffe, Judson, Matthew Ranson, and Robert Stavins. (2010). "Linking Tradable Permit Systems: A Key Element of Emerging International Climate Policy Architecture." Ecology Law Quarterly 36:789808.

Karpas, Eric, and Suzi Kerr. (2010). "Preliminary Evidence on Responses to the New Zealand Forestry Emissions Trading Scheme." Motu Working Paper 11-09, Motu Economic and Public Policy Research, Wellington, New Zealand.

Kruger, Joseph, Wallace E. Oates, and William a Pizer. (2007). "Decentralization in the EU Emissions Trading Scheme and Lessons for Global Policy." Review of Environmental Economics and Policy 1:112-133.

Levinson, Arik. (2010). "Interactions Among Climate Policy Regulations." NBER Working Paper 16109, National Bureau of Economic Research.

Market Advisory Committee to the California Air Resources Board. (2007). "Recommendations for Designing a Greenhouse Gas Cap-and-Trade System for California."

McGuinness, Meghan, and A. Denny Ellerman. (2008). "The Effects of Interactions between Federal and State Climate Policies." Massachusetts Institute of Technology Center for Energy and Environmental Policy Research Working Paper WP-2008-004.

Metcalf, Gilbert E. (2007). "A Proposal for a U.S. Carbon Tax Swap," The Hamilton Project Discussion Paper 2007-12.

Metcalf, Gilbert E., and David Weisbach. (2010). "Linking Policies When Tastes Differ: Global Climate Policy in a Heterogeneous World." Discussion Paper 2010-38, Harvard Project on International Climate Agreements, Belfer Center for Science and International Affairs, Harvard Kennedy School.

Montgomery, David W. (1972). "Markets in Licenses and Efficient Pollution Control Programs". Journal of Economic Theory 395-418.

Newell, Richard G., Adam B. Jaffe, and Robert N. Stavins. (1999). "The Induced Innovation Hypothesis and Energy-Saving Technological Change" Quarterly Journal of Economics 114(3): 941-975.

Olmstead, Sheila M., and Robert N. Stavins. (2012). "Three Key Elements of Post-2012 International Climate Policy Architecture." Review of Environmental Economics and Policy, forthcoming. 
Organization for Economic Cooperation and Development. (2011). Interactions Between Emission Trading Systems and Other Overlapping Policy Instruments. Environment Directorate, OECD, Paris.

Plumer, Bradford. (2010). “B.C.'s Carbon-Tax Experiment Seems To Be Working." The New Republic, July 27.

Popp, David. (2002). "Induced Innovation and Energy Prices" American Economic Review 92(1): 160180.

Province of Alberta. (2007). "Specified Gas Emitters Regulation." Alberta Regulation 139/2007.

Province of Alberta. (2008). Alberta's 2008 Climate Change Strategy. Ministry of Environment and Water, Edmonton.

Province of Alberta. (2011). "2010 Greenhouse Gas Emission Reduction Program Results." Ministry of Environment and Water, Edmonton. Internet: http://environment.alberta.ca/03501.html, accessed October 27, 2011.

Ramey, Valerie A., and Daniel J. Vine. (2010). “Oil, Automobiles, and the U.S. Economy: How Much Have Things Really Changed? NBER Working Paper 16067.

Sass, Bill. (2010). “Inside Alberta's Quiet Carbon Market.” Alberta Oil, November 1, 2010.

Speck, Stefan. (2008). "The Design of Carbon and Broad-Based Energy Taxes in European Countries." Vermont Journal of Environmental Law 10: 31-59.

Stavins, Robert N. (1995). "Transaction Costs and Tradeable Permits." Journal of Environmental Economics and Management 29:133-148.

Stavins, Robert N. (2003). "Experience with Market-Based Environmental Policy Instruments." Handbook of Environmental Economics, Volume I, eds. Karl-Göran Mäler and Jeffrey Vincent, Chapter 9, pp. 355-435. Amsterdam: Elsevier Science.

Stavins, Robert N. (2007). "A U.S. Cap-and-Trade System to Address Global Climate Change," The Hamilton Project Discussion Paper 2007-13.

Stavins, Robert N. (2011). "Polarized Politics Paralyze Policy." The Environmental Forum, Volume 28, Number 6, November/December, p. 16.

U.S. Congressional Budget Office. (2011). The Effects of Renewable or Clean Electricity Standards. Washington, D.C.

U.S. Energy Information Administration. (2009). Emissions of Greenhouse Gases in the United States. Washington, D.C.

U.S. Energy Information Administration. (2011). Annual Energy Outlook 2011. Washington, D.C. 
Wara, Michael. (2007). "Is the Global Carbon Market Working?" Nature, volume 445, 8 February, pp. 595-596.

Weitzman, Martin L. (1974). "Prices vs. Quantities." Review of Economic Studies 41: 477-491.

World Bank. (2010). World Development Report 2010: Development and Climate Change. Washington, D.C.

Zhang, Junjie, and Can Wang. (2011). "Co-Benefits and Additionality of the Clean Development Mechanism: An Empirical Analysis." Journal of Environmental Economics and Management 62:140-154. 